\title{
Uridylation and adenylation of RNAs
}

\author{
SONG JianBo ${ }^{1,3}$, SONG Jun ${ }^{2}$, MO BeiXin ${ }^{1 *} \&$ CHEN XueMei ${ }^{1,4,5^{*}}$ \\ ${ }^{1}$ Shenzhen Key Laboratory of Microbial Genetic Engineering, College of Life Science, Shenzhen University, Shenzhen 518060, China; \\ ${ }^{2}$ Key Laboratory of Optoelectronic Devices and Systems of Ministry of Education and Guangdong Province, College of Optoelectronic Engi- \\ neering, Shenzhen University, Shenzhen 518060, China; \\ ${ }^{3}$ Department of Biochemistry and Molecular Biology, College of Science, Jiangxi Agricultural University, Nanchang 330045, China; \\ ${ }^{4}$ Department of Botany and Plant Sciences, Institute of Integrative Genome Biology, University of California, Riverside CA 92521, USA; \\ ${ }^{5}$ Howard Hughes Medical Institute, University of California, Riverside, CA 92521, USA
}

Received September 5, 2015; accepted October 15, 2015; published online October 27, 2015

\begin{abstract}
The posttranscriptional addition of nontemplated nucleotides to the $3^{\prime}$ ends of RNA molecules can have a significant impact on their stability and biological function. It has been recently discovered that nontemplated addition of uridine or adenosine to the 3' ends of RNAs occurs in different organisms ranging from algae to humans, and on different kinds of RNAs, such as histone mRNAs, mRNA fragments, U6 snRNA, mature small RNAs and their precursors etc. These modifications may lead to different outcomes, such as increasing RNA decay, promoting or inhibiting RNA processing, or changing RNA activity. Growing pieces of evidence have revealed that such modifications can be RNA sequence-specific and subjected to temporal or spatial regulation in development. RNA tailing and its outcomes have been associated with human diseases such as cancer. Here, we review recent developments in RNA uridylation and adenylation and discuss the future prospects in this research area.
\end{abstract}

Uridylation, adenylation, miRNA, pre-miRNA, U6 snRNA, histone mRNA, rRNA

Citation: Song JB, Song J, Mo BX, Chen XM. Uridylation and adenylation of RNAs. Sci China Life Sci, 2015, 58: 1057-1066, doi: 10.1007/s11427-015-4954-9

Nontemplated addition of nucleotides to RNA $3^{\prime}$ ends has long been known, with the addition of CCA to the $3^{\prime}$ ends of tRNAs and mRNA polyadenylation being the earliest described examples [1,2]. Relatively more recently, studies reveal that nontemplated 3 ' nucleotide addition to eukaryotic RNAs is a more widespread phenomenon. Conserved posttranscriptional processes result in $3^{\prime}$ uridylation or adenylation of histone mRNAs, mRNA fragments, tRNAs, rRNAs, U6 snRNA, and mature small RNAs and their precursors, and these modifications are often associated with functional outcomes $[3,4]$. Here we discuss the evidence that reveals the functions of RNA 3' uridylation and adenylation, and explore instances where the role of these modifications is currently less clear.

*Corresponding author (email: xuemei.chen@ucr.edu; bmo@szu.edu.cn)

\section{$13^{\prime}$ uridylation affects RNA synthesis, degra- dation and function}

\subsection{Uridylation of histone mRNAs}

Histone mRNAs are the only known metazoan mRNAs that are not polyadenylated, ending instead in a conserved stem-loop sequence. The stem-loop-binding protein (SLBP) participates in nearly all aspects of histone mRNA metabolism, such as pre-mRNA processing [5], mRNA export [6], translation [7,8], and degradation [9]. Histone mRNAs are rapidly degraded at the end of the $S$ phase of the cell cycle or when DNA replication is inhibited [10,11].

In human cells, histone mRNA degradation begins with the assembly of a complex of factors, including SLBP and Exoribonuclease 1 (Eri1), on the $3^{\prime}$ end of the mRNA, re- 
sulting in the addition of uridine to the $3^{\prime}$ end of the histone mRNA. Following the oligouridylation event, the heteroheptameric Lsm1-7 complex binds to the oligo(U) tail to trigger subsequent histone mRNA degradation via both $5^{\prime}-3^{\prime}$ and $3^{\prime}-5^{\prime}$ RNA decay pathways $[10,12]$. The C-terminal extension of Lsm4 interacts directly with the $3^{\prime}$ end of the histone mRNP and this interaction is required for efficient histone mRNA degradation [13]. ZCCHC11 is the terminal uridylyl transferase responsible for human histone mRNA uridylation following inhibition or completion of DNA replication [14] (Table 1 and Figure 1). Eri1, as an exonuclease, acts on oligouridylated histone mRNAs and trims histone mRNA $3^{\prime}$ ends into the stem-loop [15]. Recently, deep sequencing revealed that histone mRNAs are degraded $3{ }^{\prime}-5^{\prime}$ in two phases: degradation into the stem loop by Eri1 followed by degradation by the exosome-associated $3^{\prime}-5^{\prime}$ ex- onuclease $\mathrm{PM} / \mathrm{Scl}-100$ [16]. If the nuclease stalls during either phase of the degradation process, further degradation is primed by re-uridylation. Multiple oligouridylation events may be required for $3^{\prime}-5^{\prime}$ degradation of histone mRNAs on polyribosomes [16].

\subsection{Uridylation of microRNA (miRNA)-directed 5' cleavage products}

By regulating gene expression in a sequence-specific manner, miRNAs play important roles in numerous biological processes. miRNAs repress target gene expression through translational inhibition as well as RNA degradation in both plants and animals, but the mechanisms of miRNA- triggered RNA degradation are largely different in plants and animals $[17,18]$. In animals, miRNAs trigger deadenylation

\section{A Uridylation of histone mRNA}

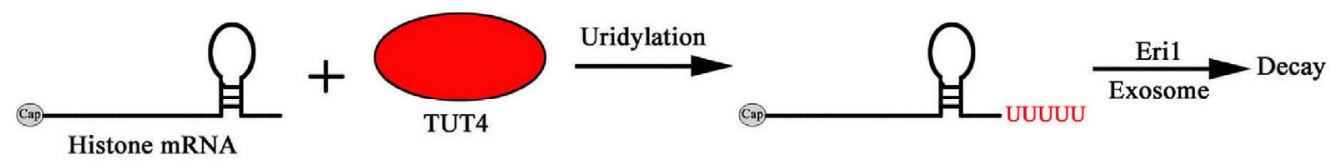

B Uridylation of pre-miRNAs

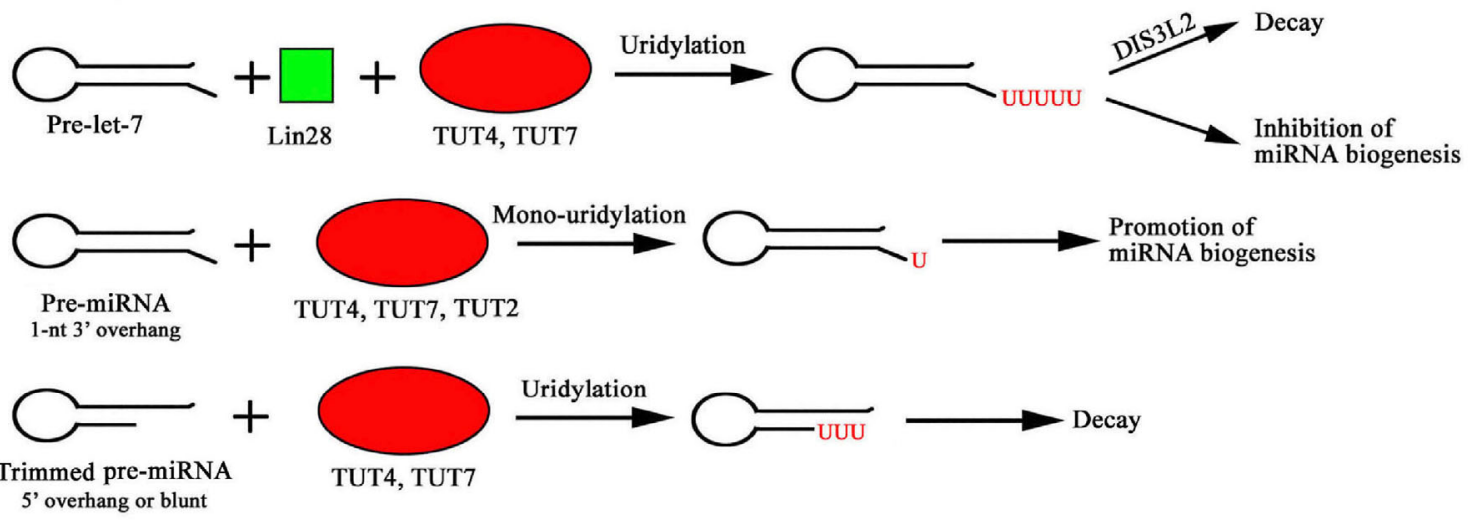

C Uridylation and adenylation of miRNAs

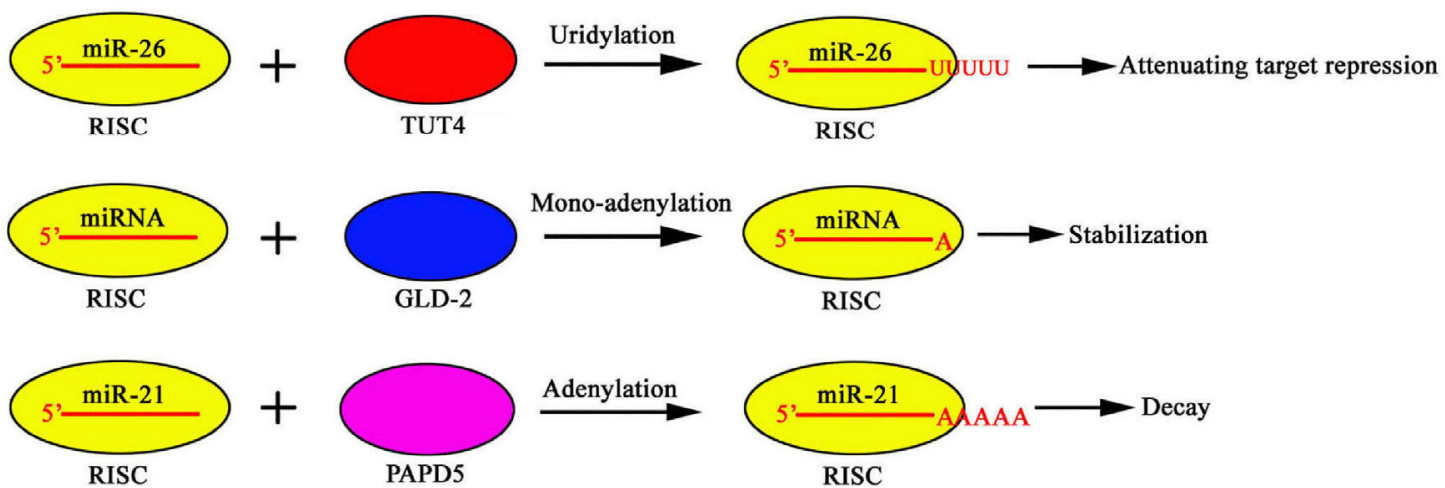

Figure 1 A summary of the substrates and outcomes of RNA uridylation and adenylation in humans. 
Table 1 Nucleotidyl transferases with known uridylation and/or adenylation activity from various species

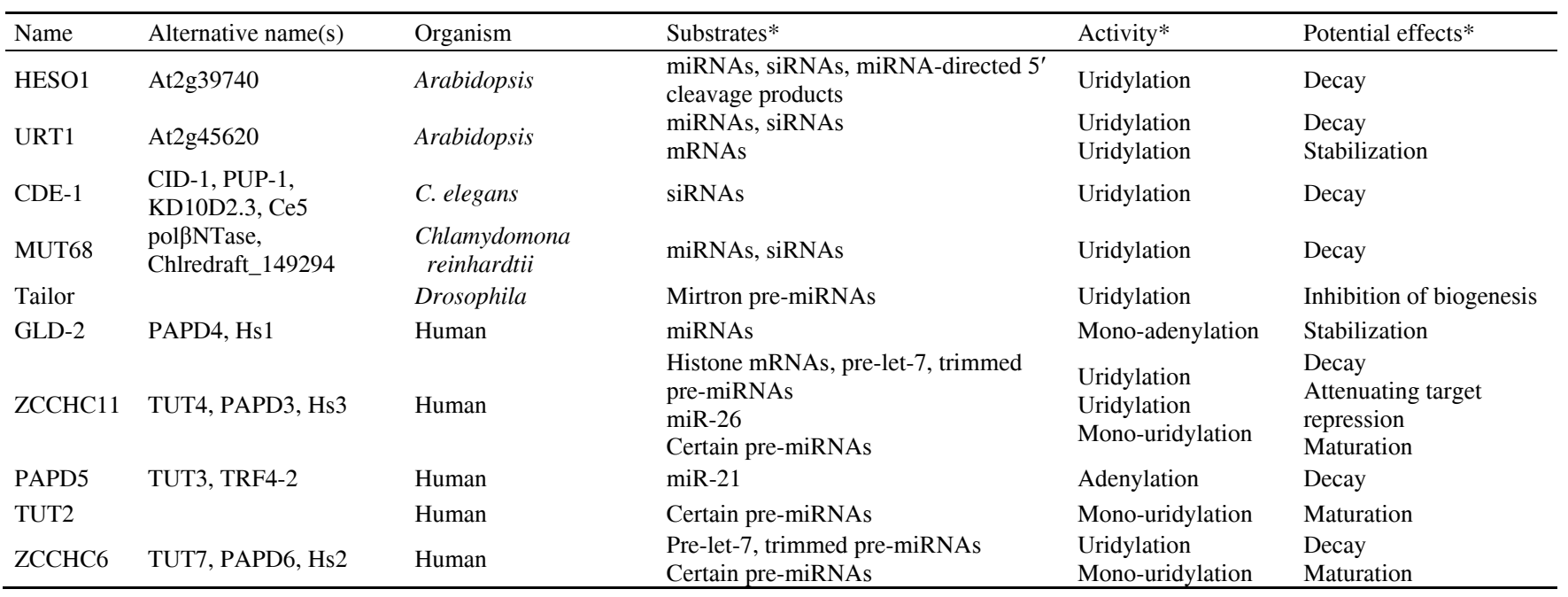

*, "Activity" and "Potential effects" refer to the "Substrates" in the same row.

followed by decapping and exonucleolytic degradation of target mRNAs [19]. Nearly all plant miRNAs and very few animal or animal viral miRNAs guide the precise endonucleolytic cleavage of target transcripts [20-22]. The $3^{\prime}$ cleavage fragments are degraded in the of $5^{\prime}-3^{\prime}$ direction by the exonuclease XRN4 in Arabidopsis [23], but degradation of the cleaved $5^{\prime}$ mRNA fragments is more complex and entails $3^{\prime}$ uridylation [24].

The presence of an oligo(U) signature posttranscriptionally added to miRNA-directed 5' cleavage products in species as diverse as Arabidopsis, mouse, and Epstein-Barr virus implies that uridylation has general importance [24]. In mammalian cell extracts, uridylation of the $3^{\prime}$ end of an RNA promotes their decapping relative to an RNA lacking the uridine tract [25]. In addition to promoting decapping, the nontemplated oligo(U) tail prevents $3^{\prime}-5^{\prime}$ exonucleolytic decay to ensure 5'-3' directional degradation [25]. In Arabidopsis, HESO1 uridylates the $5^{\prime}$ fragments resulting from miRNA-guided cleavage of target RNAs to trigger their degradation, and AGO1, the effector protein of miRNAs, is associated with HESO1 in vivo [26] (Table 1 and Figure 2B).

\subsection{Uridylation of snRNAs}

The U6 small nuclear RNA (snRNA) is a member of the evolutionarily conserved snRNA class within the eukaryotic spliceosome. Mammalian U6 snRNA is heterogeneous in size due to nontemplated $3^{\prime}$ uridylation [27]. A major form contains five terminal $U$ residues and a $2^{\prime}, 3^{\prime}$ cyclic phosphate; minor forms contain up to $12 \mathrm{U}$ residues and a $3^{\prime} \mathrm{OH}[27,28]$. These forms probably represent the dynamic nature of the U6 $3^{\prime}$ end in the spliceosome, as these forms are all present in the U4/U5/U6 tri-snRNPs [28], and are the result of two opposing enzymatic activities that elongate and trim the $3^{\prime}$ end. U6-TUTase is a terminal uridylyl transferase that posttranscriptionally $3^{\prime}$ oligouridylates U6 snRNA $[29,30]$, whereas USB 1 is a distributive $3^{\prime}-5^{\prime}$ exoribonuclease that posttranscriptionally removes uridine and adenosine nucleotides from the $3^{\prime}$ end of U6 snRNA [31]. As the length of the $U$ tail as well as the presence or absence of the 2', 3' cyclic phosphate modulates the affinity of U6 to RNA binding proteins such as La and the heteroheptameric Lsm2-8 complex [32], both of which associate with U6 during snRNP maturation and recycling, the uridylation of U6 RNA is considered an integral process in U6 RNA metabolism and splicing.

\subsection{Uridylation of small RNAs}

$3^{\prime}$ uridylation of mature small RNAs was first found in plants. Arabidopsis miRNAs or small interfering RNAs (siRNAs) are methylated on the $2^{\prime} \mathrm{OH}$ of the $3^{\prime}$ terminal ribose by the methyltransferase HUA ENHANCER 1 (HEN1) [33,34]. In henl mutants, both miRNAs and siRNAs undergo $3^{\prime}$ truncation and $3^{\prime}$ uridylation, leading to their decline in abundance [35]. Later, 3' uridylation was found to also occur to siRNAs and/or PIWI-interacting RNAs (piRNAs) in henl mutant animals, such as Tetrahymena [36]. C. elegans [37-39], Drosophila [40,41], zebra fish [42] and mouse [43]. Small RNA 3' uridylation is not restricted to hen 1 mutants; it occurs in wild type cells at a lower frequency. Studies using high throughput sequencing to profile small RNAs revealed 3' nontemplated nucleotide addition, mainly uridylation and adenylation, to mature miRNAs from viruses [44], Chlamydomonas reinhardtii [45], Drosophila [46], mouse [47], and human cells [48].

In recent years, an increasing number of terminal nucleotidyl transferases (TUTases) that uridylate small RNAs have been identified. In humans, Zcchc11 (TUT4) uridylates the 
A Uridylation of mRNA

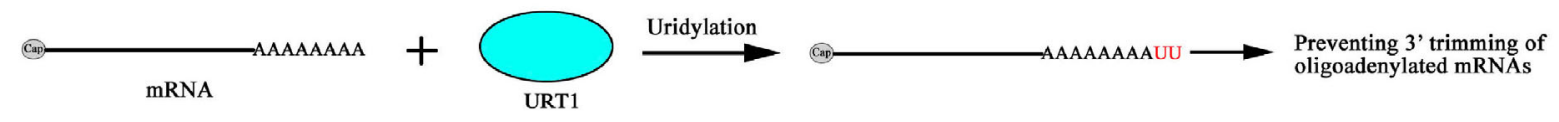

B Uridylation of miRNA - directed 5' cleavage products

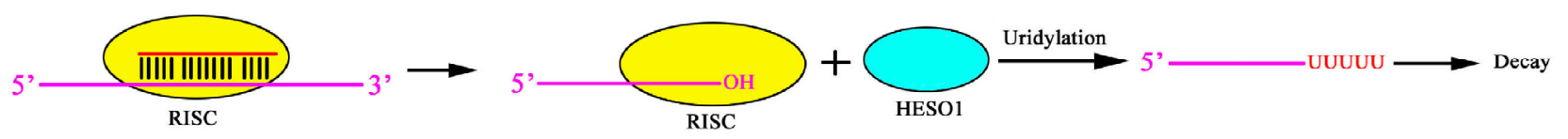

C Uridylation of small RNAs

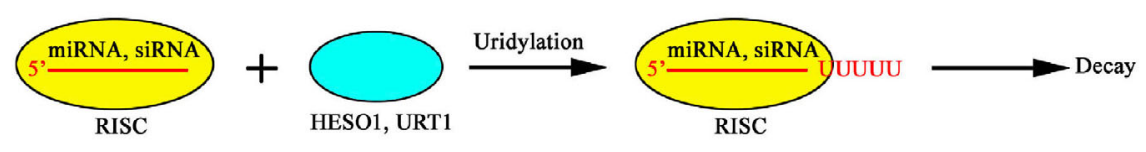

Figure 2 A summary of the substrates and outcomes of RNA uridylation in Arabidopsis.

cytokine-targeting miRNA miR-26b; the uridylation appears to attenuate the target repression activity of this miRNA such that Zcchc11 promotes the expression of cytokine genes [49] (Table 1 and Figure 1). Zcchc6 (TUT7) and Zcchc11 (TUT4) uridylate a small set of miRNAs with a common sequence motif [48] (Table 1 and Figure 1). Depletion of these TUTases in cultured human cells leads to a reduction in $3^{\prime}$ monouridylation, and interestingly, a concomitant increase in nontemplated $3^{\prime}$ monoadenylation of these miRNAs, without affecting their abundance $[48,50]$. In $C$. elegans, the nucleotidyl transferase CDE-1 uridylates siRNAs bound by the argonaute protein CSR-1 to prevent their over accumulation and loading into other argonaute proteins; CDE-1 is essential for proper meiotic and mitotic chromosome segregation [51] (Table 1). MUT68, a nucleotidyl transferase in the alga Chlamydomonas reinhardtii contributes to the presence of nontemplated uridine residues at the $3^{\prime}$ ends of small RNAs and loss of function in MUT68 results in elevated miRNA and siRNA levels [45] (Table 1). Arabidopsis HEN1 SUPPRESSOR1 (HESO1) is a nucleotidyl transferase responsible for most of the small RNA uridylation in henl mutants. HESO1 prefers UTP as the substrate nucleotide, and is completely inhibited by 2'-O-methylation in the substrate RNA [52,53]. Loss of function in $H E S O 1$ leads to increased miRNA accumulation in henl mutants [52,53]. UTP: RNA uridylyltransferase (URT1) is a functional paralog of HESO1 that is responsible for the remainder of small RNA uridylation in henl hesol mutants [54]. URT1 and HESO1 have distinct substrate preferences in vitro and act cooperatively to tail different forms of the same miRNAs in vivo [54,55] (Table 1 and Figure 2).

A surprising finding is that during the regulation of a target, the small RNA itself may be subjected to regulation by the target, which results in the posttranscriptional addition of a nontemplated uridine to the miRNA [56]. This indicates that small RNA regulatory pathways may have built-in feedback regulation. In Drosophila, the introduction of artificial RNAs with a high degree of sequence complementarity to miRNAs leads to the $3^{\prime}$ trimming and $3^{\prime}$ tailing of the cognate miRNAs [57].

\subsection{Uridylation of pre-miRNAs}

The precursors to the let-7 miRNA were first found to undergo uridylation [58]. Later, high throughput sequencing revealed that pre-miRNA $3^{\prime}$ uridylation is not limited to pre-let-7 and occurs in a developmentally regulated manner [58-62]. Studies with pre-let-7 show that the outcomes of pre-miRNA uridylation are two fold: triggering pre-miRNA degradation or promoting their processing into miRNAs (discussed below).

In human embryonic stem cells, TUT4, a nucleotidyl transferase, acts in concert with the RNA-binding protein Lin28 to uridylate pre-let-7 [58,62]. After the nuclear export of pre-let-7, Lin28 recognizes a sequence motif in the RNA loop and recruits TUT4 to add an oligo(U) tail of 10-30 nt to the 3' terminus of pre-let-7. The tail renders pre-let-7 resistant to Dicer processing and may facilitate its decay $[58,62]$ (Table 1 and Figure 1). The related nucleotidyl transferase TUT7 acts redundantly with TUT4 in this processsimultaneous knockdown of TUT7 and TUT4 leads to increased let-7 levels in embryonic stem cells [63]. The E3 ligase Trim 25 binds to the conserved terminal loop of pre-let-7 and acts as an RNA-specific cofactor to activate TUT4 for more efficient Lin28-mediated uridylation [64]. Degradation of oligouridylated pre-let-7 requires the $3^{\prime}-5^{\prime}$ exonuclease Dis3L2, which prefers U-ending RNAs as substrates [65-68].

However, in differentiated cells, pre-let-7 uridylation has a different outcome. In mouse P19 teratocarcinoma cells, which stop expressing Lin28 upon in vitro differentiation, 
profiling of pre-miRNAs revealed Lin28-dependent pre-let7 oligouridylation and Lin28-independent pre-let-7 monouridylation [59]. In human somatic cells, Lin28 is not expressed and the nucleotidyl transferases TUT7, TUT4, and TUT2 monouridylate pre-let-7; this converts pre-let-7 with a $1 \mathrm{nt} 3^{\prime}$ overhang to a better Dicer substrate with a $2 \mathrm{nt} 3^{\prime}$ overhang and thus enhances dicer processing [69] (Table 1 and Figure 1).

Related to the function of triggering degradation, pre-miRNA uridylation also plays a role in pre-miRNA quality control. High throughput sequencing of premiRNAs revealed oligouridylation of $3^{\prime}$ resected pre-let-7, suggesting that degradation intermediates of pre-let-7 need to be uridylated for further degradation [59]. In TUT4/ TUT7-depleted cells, argonaute-bound pre-miR-106b and pre-miR-18a had a higher fraction of species with blunt or 5 ' overhangs, which are likely to be degradation intermediates [60] (Table 1 and Figure 1). This suggests that uridylation helps to turnover argonaute-bound, non-productive pre-miRNAs. High throughput sequencing revealed that mirtron pre-miRNAs, which are generated from intron splicing rather than Drosha processing, are preferentially uridylated as compared to canonical pre-miRNAs [70,71]. Two recent studies identified the Drosophila nucleotidyl transferase Tailor as the enzyme that uridylates mirtron pre-miRNAs [72,73]. The specificity of Tailor for mirtron pre-miRNAs could be explained by the preference for a $3^{\prime} \mathrm{G}$ in the substrate RNA by this enzyme, as introns released from splicing should end with a $3^{\prime} \mathrm{G}[72,73]$ (Table 1).

\section{3' Adenylation affects RNA synthesis and degradation}

\subsection{Adenylation of miRNAs}

Adenylation of miRNAs was first discovered in henl mutants in Arabidopsis [35], but the impact of miRNA adenylation was unclear. In animals, uridylation and adenylation are the two most frequent miRNA $3^{\prime}$ modifications as revealed by high throughput sequencing $[46,74]$. In vertebrates, many small RNAs can be maternally deposited by the mother or expressed in the zygote to regulate early embryonic development. Profiling of small RNAs during early development in zebra fish revealed widespread miRNA $3^{\prime}$ uridylation and $3^{\prime}$ adenylation, and such modifications were found to undergo developmental stage-specific regulation [75]. Profiling of small RNAs in cells and exosomes (secreted vesicles from cells) revealed the enrichment of $3^{\prime}$ adenylation in cells and 3' uridylation in exosomes [76].

Adenylation of miR-122 has a stabilizing effect on this miRNA. GLD-2 is a cytoplasmic, non-canonical poly(A) polymerase responsible for the $3^{\prime}$ terminal monoadenylation of miR-122 and other miRNAs in mouse livers and human fibroblast cells [77,78]. In GLD2 knockout mice, miR-122 levels were selectively reduced, suggesting that $3^{\prime}$ adenylation stabilizes the miRNA [77]. In human fibroblasts, miR122 is also monoadenylated and stabilized by GLD2 [78], and the hepatitis B virus may inhibit the process of miR122 adenylation [79]. Adenylation of miRNAs may have a widespread functional impact in humans, because miRNAs in a variety of human cells are modified by adenylation $[77,78,80,81]$.

But the stabilizing effect of $3^{\prime}$ adenylation on miR-122 may not be extrapolated to other miRNAs. Another study examined the effects of GLD-2 knockdown in human THP-1 cells (GLD-2 was referred to as PAPD4 in this study) and showed that GLD-2 is responsible for the $3^{\prime}$ adenylation of many miRNAs [46] (Table 1 and Figure 1). However, the reduction in $3^{\prime}$ adenylation did not correlate with increased miRNA levels; instead it correlated with reduced expression of miRNA target genes, suggesting that adenylation reduced miRNA activity [46].

A study on human miR-21, an oncogenic miRNA implicated in numerous human diseases, concluded that adenylation of miR-21 leads to its destabilization [82]. In human THP-1 cells, 3' adenylation of miR-21 is caused by the non-canonical poly(A) polymerase PAPD5 rather than GLD-2. Knocking down either PAPD5 or the exonuclease PARN led to increased miR-21 levels and reduced miR-21 species with $3^{\prime}$ trimming, suggesting that PAPD5-mediated adenylation of miR-21 triggers $3^{\prime}-5^{\prime}$ digestion of the miRNA by PARN [82] (Table 1 and Figure 1).

\subsection{Adenylation of mRNA}

In eukaryotic cells, the cotranscriptional addition of a poly(A) tail to the $3^{\prime}$ ends of mRNA molecules is nearly universal; the poly(A) tail protects mRNAs from degradation and facilitates their translation from yeast to higher eukaryotes [1]. But in recent years, it was found that in some cases, polyadenylation leads to the degradation of mRNAs. For example, in human cells, the $\beta$-globin pre-mRNA is cotranscriptionally cleaved, oligoadenylated, and degraded by the $3^{\prime}-5^{\prime}$ nuclease exosome [83]. The mouse serum albumin (MSA) gene also undergoes cotranscriptional cleavage of the pre-mRNA near the 3 ' end of the gene, and some of the transcripts are also oligoadenylated and degraded by the exosome [83]. Pre-mRNA degradation may represent a secondary role for RNA adenylation in mammals. In Chlamydomonas, MUT68 oligoadenylates 5' RNA fragments generated by small RNA-mediated cleavage and leads to their degradation by a $3^{\prime}-5^{\prime}$ exonuclease, most likely the exosome [84].

\subsection{Adenylation of rRNAs}

Although rRNAs are not produced by RNA polymerase II 
and thus are not subjected to cotranscriptional polyadenylation as do mRNAs, in yeast, a small fraction of precursor rRNAs is posttranscriptionally modified at their $3^{\prime}$ ends by the addition of a poly(A) tail in vivo $[85,86]$. As the levels of polyadenylated precursor rRNAs dramatically increase when Rrp6p, a component of the nuclear exosome, is mutated, rRNA polyadenylation is thought to trigger exosome-mediated degradation as a surveillance mechanism to remove improperly processed rRNAs [85]. The 5'-exoribonuclease Rat1p and its associated protein Railp are also responsible for the degradation of poly (A) ${ }^{+}$pre-rRNAs [86]. 5-fluorouracil (5FU), a chemotherapeutic compound for the treatment of solid tumors, was found to inhibit this exosome-dependent surveillance pathway that degrades polyadenylated precursor rRNAs [87].

\section{Specificity and regulation of RNA uridylation and adenylation}

As discussed above, uridylation or adenylation of RNAs is a widespread phenomenon found for different RNA species and in many organisms, but these posttranscriptional processes exhibit specificity and undergo regulation. For example, miRNA 3' uridylation and adenylation exhibit sequence specificity - some miRNAs are predominantly adenylated while others are predominantly uridylated $[79,88]$. This is consistent with the fact that some nucleotidyl transferases (such as Arabidopsis URT1 and HESO1 and Drosophila Tailor) exhibit a preference for the $3^{\prime}$ nucleotide in its substrate RNA [55,72,73] (Table 1 and Figure 2). RNA-binding proteins also contribute to the recruitment of

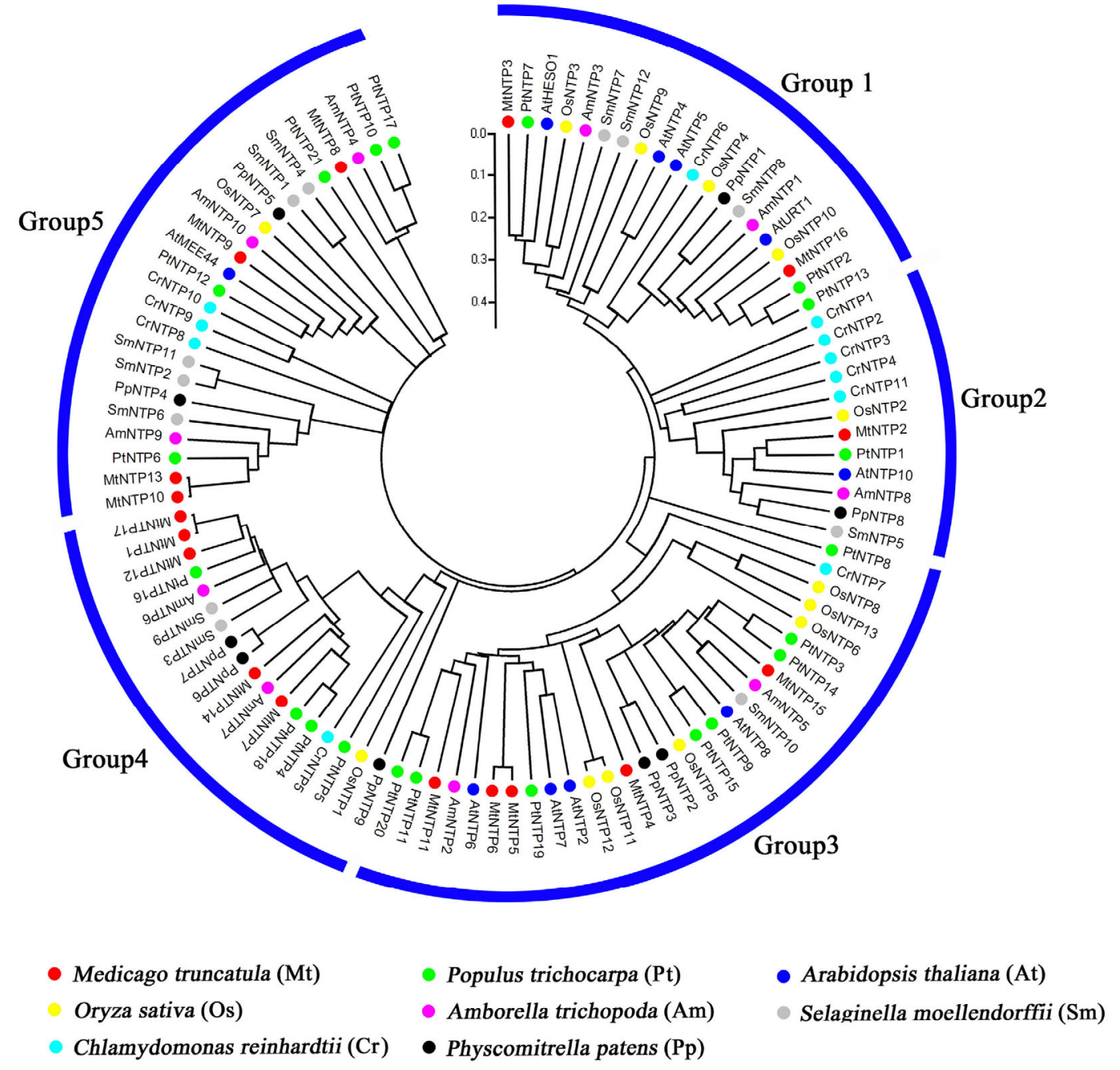

Figure 3 A phylogenetic tree of the nucleotidyl transferase protein (NTP) family from Arabidopsis thaliana (At), Oryza sativa (Os), Amborella trichopoda $(\mathrm{Am})$, Medicago truncatula $(\mathrm{Mt})$, Populus trichocarpa $(\mathrm{Pt})$, Selaginella moellendorffii $(\mathrm{Sm})$, Physcomitrella patens $(\mathrm{Pp})$ and Chlamydomonas reinhardtii (Cr). The potential NTPs from various organisms were retrieved by searches using the PFam nucleotidyl transferase domain (PF01909) [91] as the query against the protein databases for these organisms at Phytozome (http://phytozome.jgi.doe.gov). The searches were performed with the HMMER3 pipeline [92,93]. The full-length NTP protein sequences were aligned by CLUSTAL X 2.0 [94], and the alignments were used to generate an unrooted phylogenetic tree with MEGA 5.1 [95], using the p-distance method and a bootstrap value of 1,000. Evolutionary distance is indicated by the scale bar inside the figure. The NTPs used in the analysis are listed in Supplemental Table S1. 
nucleotidyl transferases to specific substrates as discussed above $[62,64]$. miRNA $3^{\prime}$ tailing appears to undergo developmental regulation. For example, during early development in Drosophila, the levels of uridylated miRNAs are higher, but in mature tissues, the levels of adenylated miRNAs are higher [89]. Patterns of uridylation and/or adenylation of miRNAs in healthy tissues are different from cancerous tissues [79].

\section{Conclusions and perspective}

Uridylation and/or adenylation are universal and conserved RNA modifications that have major impacts on the degradation, synthesis and mode of action of RNAs. Given the diverse types of modifications, such as mono- and oligo-uridylation and mono- and oligo-adenylation, and the diverse RNA substrates that undergo the modifications, it is hard to generalize on the functional outcomes of the modifications. A common theme is perhaps that a stretch of homo-oligomeric nucleotides, either A or U, tends to lead to RNA degradation by allowing exonucleases to overcome RNA secondary structures or protection by RNA binding proteins (ribosome, argonaute, etc.). Monouridylation or monoadenylation may impart different outcomes on different RNAs. Key to RNA uridylation or adenylation are nucleotidyl transferases, whose preference for UTP or ATP dictates the nature of the tail to be added and whose processivity may determine whether one or a number of nucleotides are added. Plant and animal genomes encode multiple nucleotidyl transferases [55,62] (Figure 3), many of which have not been characterized. For example, there are 10 putative nucleotidyl transferases in Arabidopsis (Figure 3), among which only HESO1 and URT1 have been studied [52-55,90] (Table 1 and Figure 2). Studying the enzymatic properties and biological functions of nucleotidyl transferases will lead to a better understanding of $3^{\prime}$ tailing in RNA metabolism.

The authors declare that they have no conflict of interest.

We thank Howard Hughes Medical Institute in the USA. This work was supported by the National Institutes of Health (GM061146), National Science Foundation (IOS-1340001), the National Natural Science Foundation of China (91440105 and 31571332).

1 Manley JL. Messenger RNA polyadenylylation: a universal modification. Proc Natl Acad Sci USA, 1995, 92: 1800-1801

2 Sprinzl M, Cramer F. The-CCA end of tRNA and its role in protein biosynthesis. Proc Natl Acad Sci USA, 1979, 22: 1-69

3 Scott DD, Norbury CJ. RNA decay via 3' uridylation. Biochim Biophys Acta, 2013, 1829: 654-665

4 Wickens M, Kwak JE. A tail tale for U. Science, 2008, 319: 1344-1345

5 Wang Z-F, Whitfield ML, Ingledue TCr, Dominski Z, Marzluff WF. The protein that binds the $3^{\prime}$ end of histone mRNA: a novel
RNA-binding protein required for histone pre-mRNA processing. Genes Dev, 1996, 10: 3028-3040

6 Sullivan KD, Mullen TE, Marzluff WF, Wagner EJ. Knockdown of SLBP results in nuclear retention of histone mRNA. RNA, 2009, 15: 459-472

7 Ling J, Morley SJ, Pain VM, Marzluff WF, Gallie DR. The histone 3'-terminal stem-loop-binding protein enhances translation through a functional and physical interaction with eukaryotic initiation factor 4G (eIF4G) and eIF3. Mol Cell Biol, 2002, 22: 7853-7867

8 Sànchez R, Marzluff WF. The stem-loop binding protein is required for efficient translation of histone mRNA in vivo and in vitro. Mol Cell Biol, 2002, 22: 7093-7104

9 Zheng L, Dominski Z, Yang X-C, Elms P, Raska CS, Borchers CH, Marzluff WF. Phosphorylation of stem-loop binding protein (SLBP) on two threonines triggers degradation of SLBP, the sole cell cycle-regulated factor required for regulation of histone mRNA processing, at the end of S phase. Mol Cell Biol, 2003, 23: 1590-1601

10 Mullen TE, Marzluff WF. Degradation of histone mRNA requires oligouridylation followed by decapping and simultaneous degradation of the mRNA both $5^{\prime}$ to $3^{\prime}$ and $3^{\prime}$ to $5^{\prime}$. Genes Dev, 2008, 22 : 50-65

11 Su W, Slepenkov SV, Slevin MK, Lyons SM, Ziemniak M, Kowalska J, Darzynkiewicz E, Jemielity J, Marzluff WF, Rhoads RE. mRNAs containing the histone 3' stem - loop are degraded primarily by decapping mediated by oligouridylation of the $3^{\prime}$ end. RNA, 2013, 19: $1-16$

12 Hoefig KP, Heissmeyer V. Degradation of oligouridylated histone mRNAs: see UUUUU and goodbye. Wiley Interdisciplinary Reviews: RNA, 2014, 5: 577-589

13 Lyons SM, Ricciardi AS, Guo AY, Kambach C, Marzluff WF. The C-terminal extension of Lsm4 interacts directly with the 3 ' end of the histone mRNP and is required for efficient histone mRNA degradation. RNA, 2014, 20: 88-102

14 Schmidt M-J, West S, Norbury CJ. The human cytoplasmic RNA terminal U-transferase ZCCHC11 targets histone mRNAs for degradation. RNA, 2011, 17: 39-44

15 Hoefig KP, Rath N, Heinz GA, Wolf C, Dameris J, Schepers A, Kremmer E, Ansel KM, Heissmeyer V. Eril degrades the stem-loop of oligouridylated histone mRNAs to induce replication-dependent decay. Nat Struct Mol Biol, 2013, 20: 73-81

16 Slevin MK, Meaux S, Welch JD, Bigler R, de Marval PLM, Su W, Rhoads RE, Prins JF, Marzluff WF. Deep sequencing shows multiple oligouridylations are required for $3^{\prime}$ to $5^{\prime}$ degradation of histone mRNAs on polyribosomes. Mol Cell, 2014, 53: 1020-1030

17 Izaurralde E. Breakers and blockers-miRNAs at work. Science, 2015, 349: 380-382

18 Voinnet O. Origin, biogenesis, and activity of plant microRNAs. Cell, 2009, 136: 669-687

19 Jonas S, Izaurralde E. Towards a molecular understanding of microRNA-mediated gene silencing. Nat Rev Genet, 2015, 16: 421-433

20 Jones-Rhoades MW, Bartel DP, Bartel B. MicroRNAs and their regulatory roles in plants. Annu Rev Plant Biol, 2006, 57: 19-53

21 Yekta S, Shih I-h, Bartel DP. MicroRNA-directed cleavage of HOXB8 mRNA. Science, 2004, 304: 594-596

22 Pfeffer S, Zavolan M, Grässer FA, Chien M, Russo JJ, Ju J, John B, Enright AJ, Marks D, Sander C. Identification of virus-encoded microRNAs. Science, 2004, 304: 734-736

23 Souret FF, Kastenmayer JP, Green PJ. AtXRN4 degrades mRNA in Arabidopsis and its substrates include selected miRNA targets. Mol Cell, 2004, 15: 173-183

24 Shen B, Goodman HM. Uridine addition after microRNA-directed cleavage. Science, 2004, 306: 997-997

25 Song M-G, Kiledjian M. 3' Terminal oligo U-tract-mediated stimulation of decapping. RNA, 2007, 13: 2356-2365

26 Ren G, Xie M, Zhang S, Vinovskis C, Chen X, Yu B. Methylation protects microRNAs from an AGO1-associated activity that uridylates 5" RNA fragments generated by AGO1 cleavage. Proc Natl 
Acad Sci USA, 2014, 111: 6365-6370

27 Lund E, Dahlberg JE. Cyclic 2',3'-phospates and nontemplated nucleotides at the 3'end of spliceosomal U6 small nuclear RNA's. Science, 1992, 255: 327

28 Tazi J, Forne T, Jeanteur P, Cathala G, Brunel C. Mammalian U6 small nuclear RNA undergoes $3^{\prime}$ end modifications within the spliceosome. Mol Cell Biol, 1993, 13: 1641-1650

29 Trippe R, Richly H, Benecke BJ. Biochemical characterization of a U6 small nuclear RNA-specific terminal uridylyltransferase. Eur J Biochem, 2003, 270: 971-980

30 Trippe R, Guschina E, Hossbach M, Urlaub H, Lührmann R, Benecke B-J. Identification, cloning, and functional analysis of the human U6 snRNA-specific terminal uridylyl transferase. RNA, 2006, 12: $1494-1504$

31 Hilcenko C, Simpson PJ, Finch AJ, Bowler FR, Churcher MJ, Jin L, Packman LC, Shlien A, Campbell P, Kirwan M. Aberrant 3' oligoadenylation of spliceosomal U6 small nuclear RNA in poikiloderma with neutropenia. Blood, 2013, 121: 1028-1038

32 Licht K, Medenbach J, Lührmann R, Kambach C, Bindereif A. 3 '-cyclic phosphorylation of U6 snRNA leads to recruitment of recycling factor p110 through LSm proteins. RNA, 2008, 14: 1532-1538

33 Yu B, Yang Z, Li J, Minakhina S, Yang M, Padgett RW, Steward R, Chen X. Methylation as a crucial step in plant microRNA biogenesis. Science, 2005, 307: 932-935

34 Yang Z, Ebright YW, Yu B, Chen X. HEN1 recognizes $21-24$ t small RNA duplexes and deposits a methyl group onto the $2^{\prime} \mathrm{OH}$ of the 3' terminal nucleotide. Nucleic Acids Res, 2006, 34: 667-675

35 Li J, Yang Z, Yu B, Liu J, Chen X. Methylation protects miRNAs and siRNAs from a 3'-end uridylation activity in Arabidopsis. Curr Biol, 2005, 15: 1501-1507

36 Kurth HM, Mochizuki K. 2'-O-methylation stabilizes Piwi-associated small RNAs and ensures DNA elimination in Tetrahymena. RNA, 2009, 15: 675-685

37 Billi AC, Alessi AF, Khivansara V, Han T, Freeberg M, Mitani S, Kim JK. The Caenorhabditis elegans HEN1 ortholog, HENN-1, methylates and stabilizes select subclasses of germline small RNAs. PLoS Genet, 2012, 8: e1002617

38 Montgomery TA, Rim YS, Zhang C, Dowen RH, Phillips CM, Fischer S, Ruvkun G. PIWI associated siRNAs and piRNAs specifically require the Caenorhabditis elegans HEN1 ortholog henn-1. PLoS Genet, 2012, 8: e1002616

39 Kamminga LM, Van Wolfswinkel JC, Luteijn MJ, Kaaij L, Bagijn MP, Sapetschnig A, Miska EA, Berezikov E, Ketting RF. Differential impact of the HEN1 homolog HENN-1 on 21U and 26G RNAs in the germline of Caenorhabditis elegans. PLoS Genet, 2012, 8: e1002702

40 Horwich MD, Li C, Matranga C, Vagin V, Farley G, Wang P, Zamore PD. The Drosophila RNA methyltransferase, DmHen1, modifies germline piRNAs and single-stranded siRNAs in RISC. Curr Biol, 2007, 17: 1265-1272

41 Saito K, Sakaguchi Y, Suzuki T, Suzuki T, Siomi H, Siomi MC. Pimet, the Drosophila homolog of HEN1, mediates 2'-O-methylation of Piwi-interacting RNAs at their $3^{\prime}$ ends. Genes Dev, 2007, 21: 1603-1608

42 Kamminga LM, Luteijn MJ, den Broeder MJ, Redl S, Kaaij LJ, Roovers EF, Ladurner P, Berezikov E, Ketting RF. Hen1 is required for oocyte development and piRNA stability in zebrafish. Embo J, 2010, 29: 3688-3700

43 Kirino Y, Mourelatos Z. The mouse homolog of HEN1 is a potential methylase for Piwi-interacting RNAs. RNA, 2007, 13: 1397-1401

44 Dölken L, Perot J, Cognat V, Alioua A, John M, Soutschek J, Ruzsics Z, Koszinowski U, Voinnet O, Pfeffer S. Mouse cytomegalovirus microRNAs dominate the cellular small RNA profile during lytic infection and show features of posttranscriptional regulation. J Virol, 2007, 81: 13771-13782

45 Ibrahim F, Rymarquis LA, Kim E-J, Becker J, Balassa E, Green PJ, Cerutti H. Uridylation of mature miRNAs and siRNAs by the MUT68 nucleotidyltransferase promotes their degradation in Chla- mydomonas. Proc Natl Acad Sci USA, 2010, 107: 3906-3911

46 Burroughs AM, Ando Y, de Hoon MJ, Tomaru Y, Nishibu T, Ukekawa R, Funakoshi T, Kurokawa T, Suzuki H, Hayashizaki Y. A comprehensive survey of $3^{\prime}$ animal miRNA modification events and a possible role for $3^{\prime}$ adenylation in modulating miRNA targeting effectiveness. Genome Res, 2010, 20: 1398-1410

47 Jones MR, Blahna MT, Kozlowski E, Matsuura KY, Ferrari JD, Morris SA, Powers JT, Daley GQ, Quinton LJ, Mizgerd JP. Zcchc11 uridylates mature miRNAs to enhance neonatal IGF-1 expression, growth, and survival. PLoS Genet, 2012, 8: e1003105

48 Thornton JE, Du P, Jing L, Sjekloca L, Lin S, Grossi E, Sliz P, Zon LI, Gregory RI. Selective microRNA uridylation by Zcchc6 (TUT7) and Zcchc11 (TUT4). Nucleic Acids Res, 2014, 42: 11777-11791

49 Jones MR, Quinton LJ, Blahna MT, Neilson JR, Fu S, Ivanov AR, Wolf DA, Mizgerd JP. Zcchc11-dependent uridylation of microRNA directs cytokine expression. Nat Cell Biol, 2009, 11: 1157-1163

50 Rissland OS, Mikulasova A, Norbury CJ. Efficient RNA polyuridylation by noncanonical poly (A) polymerases. Mol Cell Biol, 2007, 27: 3612-3624

51 van Wolfswinkel JC, Claycomb JM, Batista PJ, Mello CC, Berezikov E, Ketting RF. CDE-1 affects chromosome segregation through uridylation of CSR-1-bound siRNAs. Cell, 2009, 139: 135-148

52 Zhao Y, Yu Y, Zhai J, Ramachandran V, Dinh TT, Meyers BC, Mo B, Chen X. The Arabidopsis nucleotidyl transferase HESO1 uridylates unmethylated small RNAs to trigger their degradation. Curr Biol, 2012, 22: 689-694

53 Ren G, Chen X, Yu B. Uridylation of miRNAs by hen1 suppressor1 in Arabidopsis. Curr Biol, 2012, 22: 695-700

54 Wang X, Zhang S, Dou Y, Zhang C, Chen X, Yu B, Ren G. Synergistic and independent actions of multiple terminal nucleotidyl transferases in the $3^{\prime}$ tailing of small RNAs in Arabidopsis. PLoS Genet, 2015, 11: e1005091

55 Tu B, Liu L, Xu C, Zhai J, Li S, Lopez MA, Zhao Y, Yu Y, Ramachandran V, Ren G. Distinct and cooperative activities of HESO1 and URT1 nucleotidyl transferases in microRNA turnover in Arabidopsis. PLoS Genet, 2015, 11: e1005119

56 Baccarini A, Chauhan H, Gardner TJ, Jayaprakash AD, Sachidanandam R, Brown BD. Kinetic analysis reveals the fate of a microRNA following target regulation in mammalian cells. Curr Biol, 2011, 21: 369-376

57 Ameres SL, Horwich MD, Hung JH, Xu J, Ghildiyal M, Weng Z, Zamore PD. Target RNA-directed trimming and tailing of small silencing RNAs. Science, 2010, 328: 1534-1539

58 Heo I, Joo C, Cho J, Ha M, Han J, Kim VN. Lin28 mediates the terminal uridylation of let-7 precursor MicroRNA. Mol Cell, 2008, 32: 276-284

59 Newman MA, Mani V, Hammond SM. Deep sequencing of microRNA precursors reveals extensive $3^{\prime}$ end modification. RNA, 2011, 17: 1795-1803

60 Liu X, Zheng Q, Vrettos N, Maragkakis M, Alexiou P, Gregory BD, Mourelatos Z. A microRNA precursor surveillance system in quality control of microRNA synthesis. Mol Cell, 2014, 55: 868-879

61 Kim B, Ha M, Loeff L, Chang H, Simanshu DK, Li S, Fareh M, Patel DJ, Joo C, Kim VN. TUT7 controls the fate of precursor microRNAs by using three different uridylation mechanisms. Embo J, 2015, in presse201590931

62 Heo I, Joo C, Kim Y-K, Ha M, Yoon M-J, Cho J, Yeom K-H, Han J, Kim VN. TUT4 in concert with Lin28 suppresses microRNA biogenesis through pre-microRNA uridylation. Cell, 2009, 138: 696-708

63 Thornton JE, Chang H-M, Piskounova E, Gregory RI. Lin28-mediated control of let-7 microRNA expression by alternative TUTases Zcchc11 (TUT4) and Zcchc6 (TUT7). RNA, 2012, 18: 1875-1885

64 Choudhury NR, Nowak JS, Zuo J, Rappsilber J, Spoel SH, Michlewski G. Trim25 Is an RNA-specific activator of Lin28a/TuT4mediated uridylation. Cell reports, 2014, 9: 1265-1272

65 Ustianenko D, Hrossova D, Potesil D, Chalupnikova K, Hrazdilova K, Pachernik J, Cetkovska K, Uldrijan S, Zdrahal Z, Vanacova S. 
Mammalian DIS3L2 exoribonuclease targets the uridylated precursors of let-7 miRNAs. RNA, 2013, 19: 1632-1638

66 Chang H-M, Triboulet R, Thornton JE, Gregory RI. A role for the Perlman syndrome exonuclease Dis312 in the Lin28-let-7 pathway. Nature, 2013, 497: 244-248

67 Faehnle CR, Walleshauser J, Joshua-Tor L. Mechanism of Dis312 substrate recognition in the Lin28-let-7 pathway. Nature, 2014, 514: 252-256

68 Malecki M, Viegas SC, Carneiro T, Golik P, Dressaire C, Ferreira MG, Arraiano CM. The exoribonuclease Dis3L2 defines a novel eukaryotic RNA degradation pathway. Embo J, 2013, 32: 1842-1854

69 Heo I, Ha M, Lim J, Yoon M-J, Park J-E, Kwon SC, Chang H, Kim VN. Mono-uridylation of pre-microRNA as a key step in the biogenesis of group II let-7 microRNAs. Cell, 2012, 151: 521-532

70 Chung W-J, Agius P, Westholm JO, Chen M, Okamura K, Robine N, Leslie CS, Lai EC. Computational and experimental identification of mirtrons in Drosophila melanogaster and Caenorhabditis elegans. Genome Res, 2011, 21: 286-300

71 Westholm JO, Ladewig E, Okamura K, Robine N, Lai EC. Common and distinct patterns of terminal modifications to mirtrons and canonical microRNAs. RNA, 2012, 18: 177-192

72 Bortolamiol-Becet D, Hu F, Jee D, Wen J, Okamura K, Lin C-J, Ameres SL, Lai EC. Selective suppression of the splicing-mediated microRNA pathway by the terminal uridyltransferase Tailor. Mol Cell, 2015, 59: 217-228

73 Reimão-Pinto MM, Ignatova V, Burkard TR, Hung J-H, Manzenreither RA, Sowemimo I, Herzog VA, Reichholf B, Fariña-Lopez S, Ameres SL. Uridylation of RNA hairpins by tailor confines the emergence of microRNAs in Drosophila. Mol Cell, 2015, 59: 203-216

74 Kim Y-K, Heo I, Kim VN. Modifications of small RNAs and their associated proteins. Cell, 2010, 143: 703-709

75 Wei C, Salichos L, Wittgrove CM, Rokas A, Patton JG. Transcriptome-wide analysis of small RNA expression in early zebrafish development. RNA, 2012, 18: 915-929

76 Koppers-Lalic D, Hackenberg M, Bijnsdorp IV, van Eijndhoven MA, Sadek P, Sie D, Zini N, Middeldorp JM, Ylstra B, de Menezes RX. Nontemplated nucleotide additions distinguish the small RNA composition in cells from exosomes. Cell reports, 2014, 8: 1649-1658

77 Katoh T, Sakaguchi Y, Miyauchi K, Suzuki T, Kashiwabara S-i, Baba T, Suzuki T. Selective stabilization of mammalian microRNAs by $3^{\prime}$ adenylation mediated by the cytoplasmic poly (A) polymerase GLD-2. Genes Dev, 2009, 23: 433-438

78 Burns DM, D'Ambrogio A, Nottrott S, Richter JD. CPEB and two poly (A) polymerases control miR-122 stability and p53 mRNA translation. Nature, 2011, 473: 105-108

79 Li S-C, Tsai K-W, Pan H-W, Jeng Y-M, Ho M-R, Li W-H. MicroRNA 3'end nucleotide modification patterns and arm selection preference in liver tissues. BMC Syst Biol, 2012, 6: S14

80 Plé H, Landry P, Benham A, Coarfa C, Gunaratne PH, Provost P. The repertoire and features of human platelet microRNAs. PLoS ONE, 2012, 7: e50746

81 Lee M, Choi Y, Kim K, Jin H, Lim J, Nguyen TA, Yang J, Jeong M, Giraldez AJ, Yang H. Adenylation of maternally inherited microRNAs by Wispy. Mol Cell, 2014, 56: 696-707

82 Boele J, Persson H, Shin JW, Ishizu Y, Newie IS, Søkilde R, Hawkins SM, Coarfa C, Ikeda K, Takayama K-i. PAPD5-mediated 3'adenylation and subsequent degradation of miR-21 is disrupted in proliferative disease. Proc Natl Acad Sci USA, 2014, 111: 11467-11472

83 West S, Gromak N, Norbury CJ, Proudfoot NJ. Adenylation and exosome-mediated degradation of cotranscriptionally cleaved pre-messenger RNA in human cells. Mol Cell, 2006, 21: 437-443

84 Ibrahim F, Rohr J, Jeong W-J, Hesson J, Cerutti H. Untemplated oligoadenylation promotes degradation of RISC-cleaved transcripts. Science, 2006, 314: 1893-1893

85 Kuai L, Fang F, Butler JS, Sherman F. Polyadenylation of rRNA in Saccharomyces cerevisiae. Proc Natl Acad Sci USA, 2004, 101: 8581-8586

86 Fang F, Phillips S, Butler JS. Rat1p and Railp function with the nuclear exosome in the processing and degradation of rRNA precursors. RNA, 2005, 11: 1571-1578

87 Fang F, Hoskins J, Butler JS. 5-fluorouracil enhances exosome-dependent accumulation of polyadenylated rRNAs. Mol Cell Biol, 2004, 24: 10766-10776

88 Berezikov E, Robine N, Samsonova A, Westholm JO, Naqvi A, Hung J-H, Okamura K, Dai Q, Bortolamiol-Becet D, Martin R. Deep annotation of Drosophila melanogaster microRNAs yields insights into their processing, modification, and emergence. Genome Res, 2011, 21: 203-215

89 Fernandez-Valverde SL, Taft RJ, Mattick JS. Dynamic isomiR regulation in Drosophila development. RNA, 2010, 16: 1881-1888

90 Sement FM, Ferrier E, Zuber H, Merret R, Alioua M, Deragon J-M, Bousquet-Antonelli C, Lange H, Gagliardi D. Uridylation prevents 3' trimming of oligoadenylated mRNAs. Nucleic Acids Res, 2013, 41: 7115-7127

91 Bateman A, Coin L, Durbin R, Finn RD, Hollich V, Griffiths-Jones S, Khanna A, Marshall M, Moxon S, Sonnhammer EL. The Pfam protein families database. Nucleic Acids Res, 2004, 32: D138-D141

92 Eddy SR. A new generation of homology search tools based on probabilistic inference. In: Genome Inform, 2009. 205-211

93 Finn RD, Clements J, Eddy SR. HMMER web server: interactive sequence similarity searching. Nucleic Acids Res, 2011, in pressgkr367

94 Larkin MA, Blackshields G, Brown N, Chenna R, McGettigan PA, McWilliam H, Valentin F, Wallace IM, Wilm A, Lopez R. Clustal W and Clustal X version 2.0. Bioinformatics, 2007, 23: 2947-2948

95 Tamura K, Peterson D, Peterson N, Stecher G, Nei M, Kumar S. MEGA5: molecular evolutionary genetics analysis using maximum likelihood, evolutionary distance, and maximum parsimony methods. Mol Biol Evol, 2011, 28: 2731-2739 


\section{Biographical Sketch}

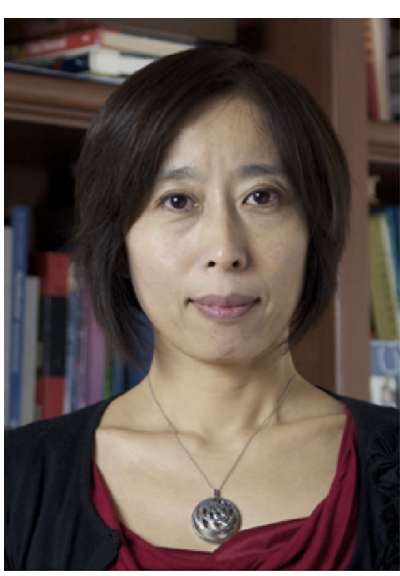

Chen XueMei grew up in Harbin and graduated with her B.S. degree in Biology from Peking University in 1988. At Peking University, she was selected to participate in the CUSBEA (China-US Biology Examinations and Admissions) program that provided opportunities for Chinese students to pursue Ph.D. studies in US institutions. She received a Ph.D. degree in Biochemistry from Cornell University in 1995. After postdoctoral training from 1995 to 1998 at California Institute of Technology, she started her Assistant Professor position in 1999 at the Waksman Institute at Rutgers University. She was promoted to Associate Professor in 2005 and won the Board of Trustees Research Fellowship for Scholarly Excellence at Rutgers University. She moved to University of California, Riverside in 2005 as an Associate Professor and was promoted to Professor in 2009 and Distinguished Professor in 2013. In 2006, she won the Charles Albert Shull award from American Society of Plant Biologists. In 2011, she was selected to be a Howard Hughes Medical Institute-Gordon and Betty Moore Foundation investigator. In the same year, she was elected an AAAS (American Association for the Advancement of Science) Fellow. In 2013, she was elected to the US National Academy of Sciences. Her major scientific contributions include the discovery of microRNAs from plants and the dissection of their biogenesis, modification, degradation, mode of action, and developmental functions.

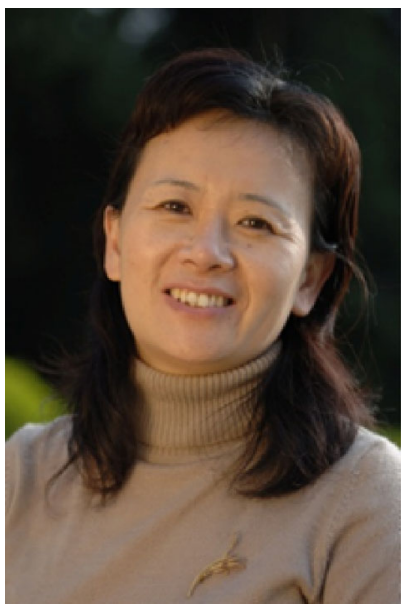

Mo BeiXin got her B.S. Degree in biology from Peking University in 1988, and her Ph.D. in plant molecular biology from University of Guelph in 2003. From April 2003 to September 2004, she worked in the Chinese University of Hong Kong as a postdoctoral fellow. After that, she joined the College of Life Sciences, Shenzhen University (SZU), where she is now a professor and Vice Dean of the college. During the years that she works in SZU, her efforts have been distributed between teaching, research and public service. She completed several national and provincial education reform projects, and won many awards. For example, the Plant Physiology course that she has been teaching was awarded the National Bilingual Teaching Demonstration course. Her current research is largely focused on the mechanisms of small RNA biogenesis, and stability, trying to understand the biological significance of the post-transcriptional addition of nontemplated nucleotides to the $3^{\prime}$ ends of RNA molecules on their stability and biological function. She is also undertaking efforts to identify new players that are involved in the cell-to-cell movement of small RNAs in plants.

Open Access This article is distributed under the terms of the Creative Commons Attribution License which permits any use, distribution, and reproduction in any medium, provided the original author(s) and source are credited. 